\title{
COVID 19 in pregnancy: Initial experience in India
}

Gaurav Desai ${ }^{1}$

${ }^{1}$ Seth GS Medical College and King Edward Memorial Hospital

April 28, 2020

Gaurav S Desai*

Department of Obstetrics and Gynecology

Bandra Bhabha Municipal General Hospital

Mumbai, India

Corresponding Author

Gaurav S Desai MS FCPS

Department of Obstetrics and Gynecology

Bandra Bhabha Municipal General Hospital

Mumbai, India

$+91-8169936775$

Running title: COVID 19 in pregnancy

Author contributions: GSD was responsible for this manuscript

\section{Hosted file}

COVIDP . docx available at https://authorea.com/users/314500/articles/444838-covid-19-in-pregnancyinitial-experience-in-india 


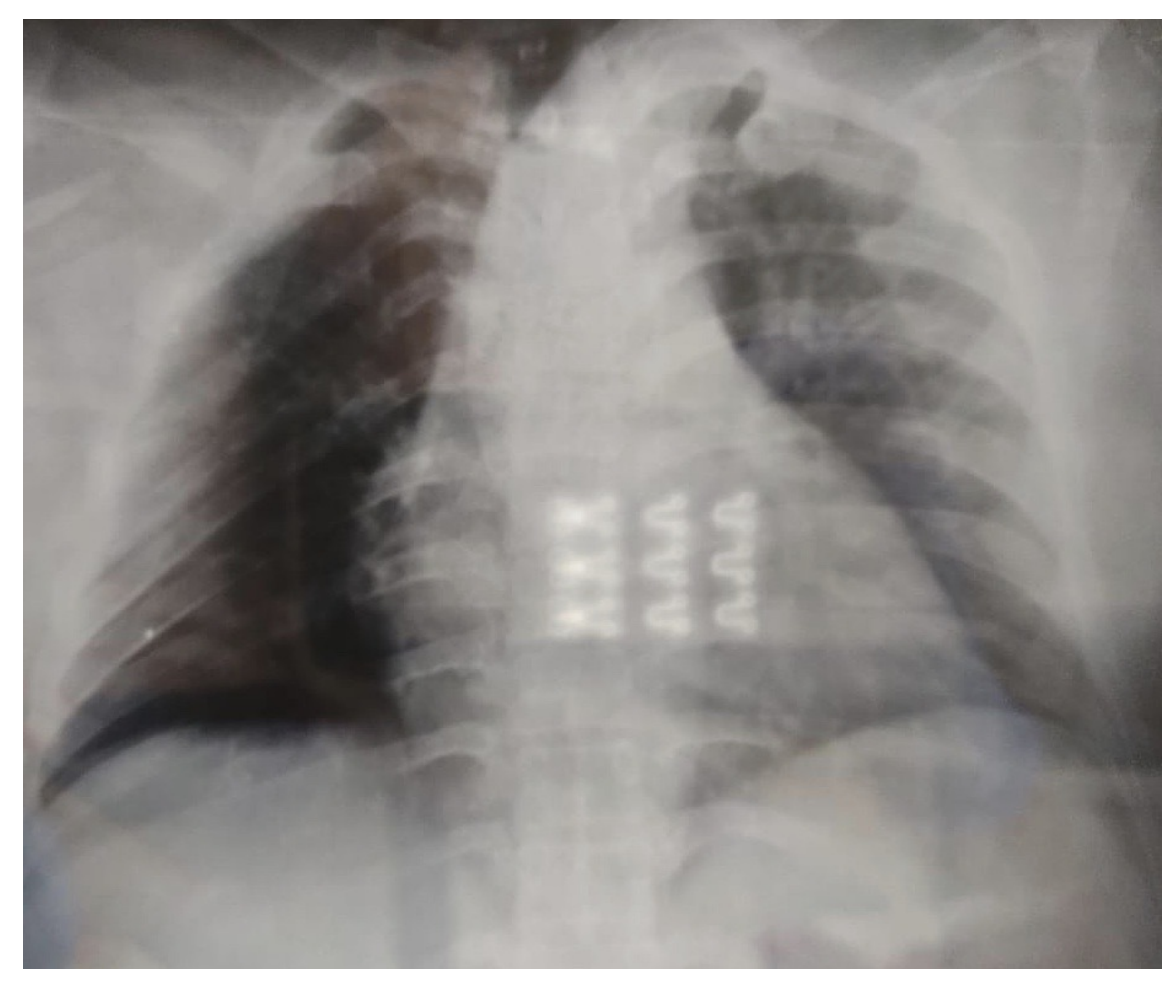

